\title{
Trabajo no remunerado y trabajo negro en España
}

\section{Enric Sanchis}

Universitat de València. Departament de Sociologia i Antropologia Social

enric.sanchis@uv.es

\section{Resumen}

El trabajo irregular y el no remunerado tienen una importancia considerable en el Estado español, por lo que el análisis de la estructura y evolución del empleo no puede hacerse al margen de ellos. En este artículo se ofrece una visión de conjunto de ambos fenómenos a partir de algunas de las investigaciones llevadas a cabo durante los últimos años. Casi la totalidad del trabajo no remunerado se hace en el ámbito de las relaciones familiares. Se calcula que dos tercios de la carga total de trabajo que soporta la economía española es trabajo doméstico no remunerado, mayoritariamente hecho por mujeres. No obstante, el trabajo voluntario no familiar equivale aproximadamente a un cuarto de millón de empleos a tiempo completo. Finalmente, algo más de uno de cada cinco ocupados españoles trabaja en la economía sumergida, y el tipo de irregularidad más frecuente es la de no estar dado de alta en la Seguridad Social.

Palabras clave: trabajo doméstico, voluntariado, economía sumergida.

\section{Abstract. Unpaid work and undeclared work in Spain}

Undeclared and unpaid work have considerable importance in Spain and so it is impossible to leave them out of any discussion of the structure and evolution of employment in Spain. This article provides an overview of both practices based on a number of studies undertaken in recent years. Almost the whole of unpaid work is to be found located in the family. It has been estimated that almost two thirds of the total work upon which the Spanish economy is based consists of unpaid domestic work, most of which is carried out by women. Nevertheless, voluntary unpaid work outside the family has been estimated as being equivalent to a quarter of a million full jobs. Finally, more than one in five in the working population in Spain are located in the 'black'economy. The most common irregularity is for workers not to be declared to or covered by the social security system,

Key words: domestic work, unpaid work, undeclared work.

\section{Sumario}

$\begin{aligned} \text { El trabajo doméstico } & \text { Dos reflexiones finales } \\ \text { El trabajo voluntario } & \text { Post scriptum } \\ \text { El trabajo negro } & \text { Bibliografía }\end{aligned}$

El tamaño de la economía sumergida 
El nacimiento de la sociedad industrial capitalista en pleno Siglo de las Luces provocó cambios fundamentales en el mundo del trabajo. En el marco de las sociedades premodernas tenía pleno sentido definir lo que hoy entendemos por trabajo como cualquier actividad mediante la cual el hombre produce todo aquello que necesita para satisfacer sus necesidades. En el nuevo marco se produjo una escisión entre espacio y tiempo de trabajo y de no trabajo que sólo era la manifestación externa de otras diferenciaciones más profundas, entre economía y sociedad, entre el ámbito de la producción económica y el de la reproducción social (Mingione, 1993: 169 y s.). La naciente economía política comenzó a generar conceptos que permitieran aprehender los nuevos hechos sociales, con lo que se inició un largo proceso que culminó en las primeras décadas del siglo XX, cuando el trabajo fue redefinido como empleo: cualquier actividad realizada a cambio de una remuneración. Todas las demás actividades dejaron de tener significación económica.

Hoy sabemos que el ámbito de la producción económica no es sino la parte emergida de un iceberg sustentada en el ámbito de la reproducción social, en el que también se trabaja, aunque ese "trabajo» no se explicite como empleo. También sabemos que esa parte emergida está trufada de ciertas formas de empleo irregular (informal) que escapan a los instrumentos de observación convencionales y que son abundantes en su línea de flotación. Todo ello constituye la llamada «economía sumergida», que en las sociedades avanzadas ha sido objeto de análisis desde hace al menos dos décadas. Estos análisis permiten concluir que no es posible comprender plenamente la estructura y la evolución del empleo formal sin tener en cuenta lo que está pasando en el ámbito del empleo informal así como en el de la reproducción social. Cierto es que los estudiosos de la economía sumergida han fijado preferentemente su atención en lo que aquí se va a llamar "trabajo irregular», pero sin perder de vista nunca que el trabajo desempeñado en los márgenes del sistema económico forma parte de la misma. Así, en una reflexión reciente sobre la economía sumergida en España, se entiende por tal «ciertas formas de trabajo definidas como "no trabajo", es decir, como "no productivas" [...] y determinados tipos de actividad económica que devengando dinero, normalmente un salario, eluden las reglamentaciones estatales y/o no son registradas por las estadísticas oficiales» (Ybarra y otros, 2002: 279-280).

El objetivo de este artículo es ofrecer una visión de conjunto y sistematizada de la extensión y las características del trabajo irregular y no remunerado en el Estado español a partir de algunas de las investigaciones llevadas a cabo durante los últimos años, en el convencimiento de que tanto en uno como en otro residen algunas de las claves interpretativas de las transformaciones que está experimentando el ámbito del empleo formal. Mientras el trabajo irregular se materializa en empleos, el no remunerado se considera que es una actividad no productiva que, por tanto, se hace al margen del mercado laboral. Ambos tipos de trabajo forman parte de lo que aquí vamos a llamar genéricamente la otra economía: una serie de actividades no incluidas en la economía oficial pero cuya relevancia económica ya no se discute. 
La otra economía es todo menos homogénea, lo que explica la variedad de denominaciones y los intentos de analizarla desde perspectivas metodológicas diferentes que guardan correspondencia con los distintos problemas que se pretende abordar. La línea siempre imprecisa que marca la frontera con la economía oficial puede trazarse en función de tres criterios: estadístico, jurídico y económico (Reyneri, 1996: 218). El criterio estadístico remite a la existencia de actividades no registradas por las estadísticas económicas básicas, como la Contabilidad Nacional o la Encuesta de Población Activa (EPA). En este sentido, la economía oficial es la estadísticamente observada, mientras la otra permanece oculta. En función del criterio jurídico aparecen dos tipos básicos de otra economía:

1) todas aquellas actividades que, por su misma naturaleza, son definidas como ilegales, que forman parte de la economía criminal;

2) actividades productivas convencionales que se llevan a cabo infringiendo la legislación fiscal o laboral.

Desde la perspectiva de ésta última, nos encontramos con el trabajo irregular, dentro del cual interesa destacar particularmente el caso del trabajo negro. Finalmente, el criterio económico utiliza el mercado y/o el dinero como factor discriminante, distinguiéndose entre economía formal e informal. Desde este punto de vista, que se solapa inevitablemente con el estadístico, el hecho social más significativo es el trabajo no remunerado, que al no ser empleo no implica para quienes lo hacen la consideración de ocupados. Los tipos principales de trabajo no remunerado son el (no) trabajo doméstico y el (no) trabajo voluntario, si bien debe señalarse que no son las únicas formas de otra economía que define este punto de vista.

Podemos inspirarnos en Polanyi (1994) para establecer cierta correspondencia entre la distinción formal/informal y sus dos definiciones (substantiva y formal) de economía. La economía substantiva es el conjunto de actividades mediante las cuales una sociedad se procura todo aquello que necesita para su subsistencia. La forma de organizar estas actividades, de integrarlas en la sociedad, y su localización (precisa o difusa) dentro del espacio social cambian según el tipo de sociedad. Y según el tipo de sociedad tendremos respuestas diferentes a la pregunta múltiple acerca de cómo se decide «quién debe hacer qué, qué medios deben ser utilizados, cuánto se va a utilizar, cuándo, a quién irán los resultados productivos y en qué cantidad». La economía formal es inventada por la sociedad occidental al llegar a la modernidad y haría referencia a aquella parte de la economía substantiva organizada en el marco del «complejo mercado-dinero-precio». De esta manera, por ejemplo, las actividades realizadas en el marco de relaciones de reciprocidad quedarían fuera del ámbito de la economía.

Nos encontramos, pues, ante una amplia variedad de actividades respecto de las cuales lo primero que debe tenerse en cuenta es que los tres criterios de delimitación no siempre coinciden ubicándolas en el lado de la otra econo- 
mía. Un ejemplo claro de esto son las trabajadoras a domicilio estudiadas por Sanchis (1984) a finales de los años setenta. Estadísticamente eran opacas porque la EPA solía registrarlas como amas de casa. En términos jurídicos, eran trabajo negro porque la práctica totalidad desarrollaban su actividad sin ningún tipo de contrato. Sin embargo, trabajaban a cambio de una remuneración elaborando productos que iban a parar al mercado. Sobre las distintas formas de otra economía existe ya una rica bibliografía internacional (Bagnasco, 1986; Sanchis, 1988; Portes y otros, 1989), pero aquí sólo se considerarán los tres fenómenos ya apuntados: el trabajo doméstico, el trabajo voluntario y el trabajo irregular.

\section{El trabajo doméstico}

El trabajo doméstico es la forma más importante de trabajo no remunerado en cualquier contexto económico. Entre los años treinta y cuarenta del siglo XX pasó a primer plano la necesidad de hacer estimaciones rigurosas del producto y la renta nacionales así como de la fuerza de trabajo y el desempleo. Las discusiones técnicas relativas a cómo medir fueron inevitablemente precedidas de otras teóricas relativas a qué medir. Había que definir de manera inequívoca las nociones de producción, renta, trabajo, empleo. Había que llegar a acuerdos sobre las actividades que se incluirían en el ámbito de la economía y las que quedarían fuera del campo de observación, y había que tomar decisiones sobre el mecanismo de asignación de valor a los diferentes bienes y servicios. Como ha señalado Durán (1995: 87), «la conversión contable de un bien en su valor entraña una operación conceptual complicada, que necesita — para ser aceptable por otros- la coincidencia en múltiples supuestos tácitos que no llegan a hacerse explícitos». Las decisiones técnicas son al mismo tiempo sociales y políticas; sólo quien no esté mínimamente familiarizado con el proceder estadístico aceptará que fueron dificultades de orden técnico las que determinaron la conveniencia de no considerar el trabajo no remunerado, y no el hecho de que era desempeñado abrumadoramente por mujeres. De ahí a confundir valor con precio - que, como dijo Machado, es propio de todo necio- no había más que un paso, que se dio al desdeñar las actividades que no pasaban por el mercado. Así, frente al ámbito de la producción económica se configuró otro que hoy día se conoce como el de la reproducción social, sostenido mayoritariamente por el trabajo invisible de las mujeres.

Ha sido sobre todo la investigación de matriz feminista la que ha puesto en evidencia las distorsiones que proyecta esta práctica en el cálculo de magnitudes macroeconómicas básicas y el sesgo que provoca analizar el trabajo remunerado sin tener en cuenta lo que ocurre en el ámbito del trabajo no remunerado. Este ámbito es ocupado de manera prevaleciente por el trabajo doméstico, que no es sólo el que se lleva a cabo en el hogar, sino, más en general, el relacionado con la familia (Carrasquer y otros, 1998). En perspectiva marxista puede decirse que el sector doméstico es un sector económico como cualquier otro en el que se produce una mercancía muy especial: la fuerza de trabajo, si bien bajo 
una lógica productiva no capitalista. Si el trabajador puede presentarse en tiempo y forma en el lugar donde se lleva a cabo la producción económica es porque el sector de la reproducción social ha estado funcionando para hacerlo posible. No puede haber trabajo productivo sin trabajo reproductivo.

Fuera del contexto de las sociedades avanzadas aparece una complicación adicional al tener que considerar, junto al doméstico, el sector de la economía de subsistencia, un sector también ocupado mayoritariamente por mujeres y separado del doméstico por una línea sutilísima. Quizás podría afirmarse que la producción para el autoconsumo forma parte del sector de subsistencia mientras que la manipulación de lo producido queda dentro de la economía doméstica. En todo caso, la no consideración de esta parte de la economía siempre provocó cierta incomodidad, por lo que a partir de los años cincuenta desde Naciones Unidas se recomendaron diversos métodos para estimar la fuerza de trabajo involucrada en la producción de subsistencia y calcular su valor de manera que pudiera agregarse al PIB, al menos en aquellos países donde su importancia no podía ponerse en duda. Ahora bien, la doble presencia de la mujer en la economía doméstica y en la de subsistencia, en la práctica suele provocar la infravaloración de ésta y la invisibilización del trabajo femenino (Benería, 1999: 324-325).

Ya en los años setenta del siglo XX el debate fructífero entre ciertas corrientes del pensamiento feminista y del marxista consiguió que se comenzara a aceptar la pertinencia de considerar el ámbito de la reproducción social como un sector productivo, y el trabajo doméstico como un tipo de trabajo caracterizado por ser eminentemente femenino, desarrollarse al margen de la relación salarial y, en consecuencia, "permanecer invisible incluso a los ojos de las personas que lo llevan a cabo" (Carrasquer y otros, 1998: 96). La Primera Conferencia Mundial de la Mujer celebrada en Nairobi en 1985 supuso un avance significativo en este sentido, pues desde Naciones Unidas se comienza a fomentar el estudio y la cuantificación del trabajo doméstico y se propone la elaboración de una contabilidad nacional separada o complementaria que permita registrar la producción no remunerada de los bienes y servicios que hacen los hogares.

La perspectiva que da el tiempo transcurrido desde entonces permite señalar algunas de las razones que explicaban y que explican el interés por este tipo de ejercicios estadísticos; un interés despertado y alimentado por el movimiento feminista, cuya influencia probablemente "ha sido determinante como factor de sensibilización sobre la importante contribución que el trabajo doméstico sigue ejerciendo en las dinámicas de reproducción de la población, y por lo tanto del conjunto del sistema social» (Meseguer, 2003: 129). En primer lugar, se trata de que la sociedad valore en su justa medida la importancia del trabajo doméstico y, de paso, el papel que la mujer desempeña en él; también de tener una visión más realista de las desigualdades en el reparto del trabajo remunerado y no remunerado, tanto en el hogar como en el conjunto de la sociedad. Todo ello en el contexto de la lucha por la igualdad entre los sexos y, más recientemente, en relación con las cuestiones que plantea la incorporación 
masiva de las mujeres al mercado de trabajo en las sociedades avanzadas (remodelación de los roles y las estructuras familiares, comportamiento de la fecundidad, políticas sociales). En segundo lugar, como ya se ha apuntado, la necesidad de revisar la estimación de agregados como el PIB y la población activa, lo cual es particularmente evidente en el caso de los países no desarrollados, pues hoy día sabemos que en muchos de ellos el trabajo no remunerado constituye al menos la mitad de la actividad económica, lo cual debilita la pretensión de que siga excluido de las cuentas nacionales. En los países desarrollados el fenómeno tiene otras dimensiones, pero no por ello puede considerarse irrelevante.

El estudio del trabajo no remunerado tiene que hacer frente a dos tipos de problemas: estimar el tiempo utilizado en él y atribuir significado económico (monetario) a ese tiempo o a los bienes y servicios producidos durante el mismo. Asumiendo la trascendencia del tema, en distintos países, así como desde Eurostat, se han llevado a cabo encuestas de empleo del tiempo y se han aplicado diversos procedimientos de asignación de valor económico al trabajo doméstico. A raíz de estas investigaciones, puede afirmarse que en la mayoría de los países desarrollados se dedica al menos tanto tiempo al trabajo no remunerado como al remunerado: «el tiempo destinado al trabajo remunerado es la actividad más prolongada (después del sueño) de una parte de la población, pero en su conjunto, el tiempo destinado a trabajo no remunerado (trabajo doméstico, fundamentalmente) es aún mayor que el anterior» (Durán, 2000: 99); un tiempo que es sobre todo tiempo de mujeres. Esto es particularmente cierto en España. A principios del siglo XXI, la economía española mantiene una estructura de tipo iceberg en el sentido de que dos tercios de la carga total de trabajo corresponden al que se lleva a cabo «en el seno de los hogares en condiciones no laborales, esto es, no remunerado, y solamente un tercio en condiciones de intercambio directo por dinero» (Durán, 2000a: 120).

En España la mayor parte del trabajo no remunerado es de tipo familiar doméstico y lo hacen las mujeres:

En el promedio semanal, los varones dedican el 62\% de su tiempo de trabajo al trabajo remunerado, en tanto que las mujeres dedican el $84 \%$ de su tiempo de trabajo al trabajo no remunerado. [...] La jornada real de trabajo (remunerado más no remunerado) a lo largo del año es el doble para las mujeres [...] Los varones sólo desarrollan un tercio del trabajo total requerido para mantener a la sociedad española en los niveles de bienestar (monetario y no monetario) que actualmente disfruta, aunque obtienen el $69 \%$ del trabajo con contrapartidas monetarias directas. [...] El nivel de vida del país se mantiene gracias a la aportación de una enorme cantidad de trabajo no remunerado, del que se adscribe a las mujeres el $80 \%$. Y según todas las encuestas de opinión, las mujeres españolas desearían cambiar esta situación por una relación diferente con la estructura productiva y con el mercado de trabajo (Durán, 2000: 110-111).

Tales deseos de cambio siguen tropezando con la solidez de la estructura familiar tradicional, de lo que encontramos un buen indicador en la última 
Encuesta de calidad de vida en el trabajo (MTAS, 2003): el 65,7\% de las mujeres ocupadas declara dedicarse además a «las labores del hogar», frente a sólo el $8,1 \%$ de los hombres (casi el mismo porcentaje que se obtiene al sumar el de hombres que viven solos y el de familias constituidas por el padre y los hijos solteros). La última Encuesta de empleo del tiempo (INE, 2004) también sigue registrando el reparto desigual de la carga total de trabajo entre hombres y mujeres según sea remunerado o no: en un día promedio los hombres dedican $3.37 \mathrm{~h}$ a trabajo y $1.30 \mathrm{~h}$ a hogar y familia, las mujeres $1.44 \mathrm{~h}$ y $4.24 \mathrm{~h}$, respectivamente. Sin embargo, el hecho de que el porcentaje de ocupadas que están al mismo tiempo estudiando duplique el de ocupados (6,4 frente a 3,1, según la primera encuesta) puede interpretarse como otro indicio de que las mujeres no van a seguir reproduciendo el modelo familiar en que fueron socializadas.

El volumen relativo de trabajo doméstico en España pone en evidencia varias cosas además de la legitimidad que asiste a las mujeres cuando reivindican estar en la sociedad de otra manera. En primer lugar, la existencia de una demanda de servicios en gran medida insolvente que si no fuese satisfecha mediante el trabajo doméstico debería ser atendida por el Estado o por organizaciones sin ánimo de lucro. En segundo lugar, que las dificultades de las españolas en el mercado de trabajo - reflejadas en una tasa de actividad muy baja y una tasa de paro muy alta - tienen mucho que ver con la inhibición del Estado en la prestación de aquellos servicios que son cubiertos con su (no) trabajo doméstico. Dicho de otra forma, en España las mujeres hacen gratis en casa lo que hacen en otros países ocupando un empleo remunerado por el Estado en el sector de servicios sociales (Navarro, 2002). En la España de finales del siglo XX, «para sustituir la dedicación de los familiares que cuidan diariamente enfermos por trabajadores asalariados harían falta 690.559 trabajadores a tiempo completo" (Durán, 1999: 244). Sin ir tan lejos, imaginemos sólo un momento qué ocurriría con el nivel de costes y la estructura organizativa de un hospital que no pudiera contar con la figura del acompañante no remunerado del internado. Finalmente, si en el cálculo del PIB per cápita se integrara el trabajo no remunerado, las diferencias entre países no serían las mismas. Lógicamente, el PIB aumentaría en todos ellos, pero este aumento sería mayor en aquéllos donde el trabajo no remunerado fuese relativamente más importante.

Hay diferentes procedimientos para asignar valor económico al trabajo no remunerado (Waring, 1994: 317 y s.). Durán (2000: 113) utiliza dos: valorarlo al mismo precio que el remunerado o suponer que el primero es un 20 por ciento más barato que el segundo. Aplicando estos criterios a los datos de la Contabilidad Nacional española y teniendo en cuenta las encuestas sobre uso del tiempo, llega a la conclusión de que hacia finales del siglo XX el PIB se habría al menos duplicado, al aumentar entre un mínimo del 102 y un máximo del 128 por ciento. Pero lo más relevante es que tal incremento no se da en ningún otro país de la OCDE o de la UE, pues en la mayoría de ellos el PIB sólo aumentaría entre el 40 y el 60 por ciento. Piénsese ahora en las transfe- 
rencias que recibe España de la UE a causa de su bajo PIB per cápita y en lo que ocurriría con ellas si las cuentas nacionales incluyeran el trabajo doméstico. Como dice Durán (1997: 28), «los indicadores de PIB o renta tienen poco sentido si no se constata, simultáneamente, que en países como Dinamarca se obtienen con el 68 por 100 de la carga global de trabajo, mientras que en países como España u Holanda se obtienen solamente con el 35 por 100 de esta carga». Así, niveles similares o diferencias pequeñas en magnitudes como la renta o el producto per cápita pueden llevar a conclusiones distorsionadas sobre la economía real o el nivel de vida relativo en países que presentan grandes diferencias en la estructura productiva no monetaria.

\section{El trabajo voluntario}

No hay una definición ampliamente compartida de trabajo voluntario. Forma parte del trabajo no remunerado y está integrado en el llamado tercer sector. Se le augura un peso creciente en la producción de bienestar social en las sociedades avanzadas, a relacionar con hechos como las tendencias demográficas, los cambios en las estructuras familiares, la imposibilidad de que el Estado ocupe el vacío generado por la disolución de los vínculos comunitarios en sociedades cada vez más atomizadas o la retirada del Estado de ciertos sectores de servicios sociales. Además es, al mismo tiempo, un generador de empleos y un indicador de la existencia de nuevos yacimientos de empleo.

El trabajo voluntario suele relacionarse tradicionalmente con la prestación de servicios personales de todo tipo a aquellos individuos que no pueden satisfacer sus necesidades recurriendo a la familia, al mercado o al Estado. Esto nos lleva en primer lugar a identificar el voluntariado con todas aquellas personas que ceden gratuitamente parte de su tiempo a las organizaciones no gubernamentales surgidas con el objetivo de paliar las carencias que sufren ciertos colectivos sociales. Ahora bien, si consideramos que todas las actividades no remuneradas que inciden sobre la cohesión social y la calidad de vida de los ciudadanos deberían ser incluidas dentro del tercer sector, enseguida surgen dudas en cuanto a los individuos a tener en cuenta o no dentro de los trabajadores voluntarios. Por ejemplo, en el País Valenciano es bien sabido que la migración procedente de otras regiones españolas ha utilizado tradicionalmente la participación en las fiestas populares como vía de integración en la comunidad local (Costa, 2002), y que la organización y el desarrollo de muchas de estas fiestas moviliza una cantidad considerable de trabajo no remunerado a lo largo de todo el año (Costa, 2002a: 333). En consecuencia, al analizar el trabajo voluntario ¿hay que tener en cuenta también el que se realiza en los casals falleros o en los cuartelillos que vertebran las fiestas de moros y cristianos? ¿Y qué hacer con la militancia de los partidos políticos? Resumiendo, toda aproximación rigurosa al trabajo voluntario debe comenzar explicitando una definición operativa del mismo que permita discriminar entre las modalidades que van a quedar dentro y fuera del campo de observación. Es lo que se hace en uno de los intentos más sistemáticos de estudiar el tema en España. 
En esa investigación se entiende por tercer sector el constituido por todas aquellas instituciones o entidades que poseen los cinco rasgos siguientes:

1) están organizadas formalmente;

2) son privadas;

3) son autónomas, es decir, tienen estatutos propios y capacidad de autocontrol institucional de sus actividades;

4) no reparten beneficios económicos entre los propietarios o los administradores (obviamente no pueden evitar ser fuente de estatus);

5) tienen un marcado grado de participación voluntaria (Ruiz, 2000: 34 y s.).

Esta definición deja fuera del campo de estudio el trabajo no remunerado que se presta en el marco de las relaciones de amistad, vecinales o familiares, excluyendo asimismo las actividades que se realizan en el marco de entidades orientadas principalmente a fines religiosos o políticos (iglesias, grupos parroquiales informales, partidos), aunque no necesariamente las que se encuadran en organizaciones dependientes de ellas y con fines específicos (es el caso de Caritas, en la que se considera que domina la orientación social). A efectos de facilitar la comparación con otros países, los investigadores clasifican todas las entidades españolas que cumplen los requisitos mencionados de acuerdo con los criterios utilizados en la Clasificación internacional de organizaciones no lucrativas. Se calcula que en 1995 en España había algo más de un cuarto de millón de entidades no lucrativas, incluyendo algo más de cincuenta mil asociaciones deportivas (Ruiz, 2000: 130). En este contexto, se considera voluntario al individuo que, siendo o no socio, desempeña actividades por cuenta de una organización no lucrativa que, si no contara con su colaboración, no tendría más remedio que remunerar.

Definiendo como voluntario en sentido amplio a quien dedica al menos una hora al mes a una organización no lucrativa y voluntario en sentido estricto a quien dedica más de dieciséis horas, y utilizando fuentes diversas, se estima que el voluntariado en sentido amplio oscila en España entre un mínimo del 9,5 y un máximo del 15 por ciento de la población mayor de 18 años. Suponiendo que la proporción sea del 9,8 por ciento, los investigadores obtienen una cifra de casi tres millones de voluntarios (2.931.219). Una estimación a su entender menos fiable que la anterior da como resultado algo más de un millón (1.026.482) de voluntarios en sentido estricto, es decir, con una dedicación mínima superior a cuatro horas semanales. Así, el voluntariado en sentido estricto supone el 35 por ciento del total de voluntarios (Ruiz, 2000: 136-143).

¿Qué significa todo esto en términos de empleo? En 1995 en el mercado de trabajo español había 12.041.900 ocupados, 548.366 de los cuales trabajaban en el tercer sector a cambio de una remuneración. Traducidas ambas magnitudes a empleos equivalentes a tiempo completo tenemos, respectivamente, 11.587.900 y 475.179 efectivos. Así pues, la ocupación remunerada en el tercer sector representaba el 4,55 por ciento de la ocupación remunerada espa- 
ñola (el 4,10 en términos de empleos equivalentes a tiempo completo). Por su parte, el trabajo voluntario suponía 253.599 empleos equivalentes a tiempo completo. En consecuencia, el empleo equivalente total del tercer sector (ocupados remunerados más voluntarios) suponía el 6,29 por ciento del empleo equivalente remunerado español. Si el trabajo voluntario fuese remunerado, su coste estaría aproximadamente en 900.000 millones de pesetas. Pueden contrastarse estos resultados con los que obtiene Pérez (2000: 134-135) en una estimación que él mismo advierte que debe ser considerada con todas las cautelas. En 1998 calcula que se prestaban más de 65 millones de horas de trabajo voluntario a la semana; dividiendo por cuarenta horas salen casi 410.000 empleos a tiempo completo. Atribuyéndoles un salario anual de 2,5 millones de pesetas, el coste del trabajo voluntario superaría el billón de pesetas al año. Finalmente, en cuanto al significado económico del tercer sector - de nuevo según Ruiz-, en 1995 representaba aproximadamente el 5 por ciento del PIB, unos cuatro billones de pesetas.

Todo esto permite concluir que el peso relativo del tercer sector español, tanto en términos de empleo como económicos, es similar al de países como Alemania, Austria, Francia o Italia; si bien en nuestro caso se distingue por la escasa contribución del Estado a sus gastos de mantenimiento (sólo un 30 por ciento de los mismos, que se reduciría al 25 por ciento si se tuviera en cuenta el precio del trabajo voluntario). Puede inferirse igualmente que la vitalidad del tercer sector pone en evidencia la insuficiencia de la oferta pública de servicios sociales. Si por una parte el trabajo voluntario es una respuesta no burocratizada a las necesidades sociales, por otra permite que el Estado se inhiba de una serie de responsabilidades que quizás debería asumir directamente (Ruiz, 2000: 167, 260, 261, 264).

Si nos ceñimos exclusivamente a las organizaciones no gubernamentales de acción social, un estudio realizado a finales de los años noventa (VV. AA., 2000) estima que por esas fechas trabajaban en ellas 1.357 .320 personas (283.684 a cambio de una remuneración y 1.073 .636 voluntarias). Traducido a equivalentes a tiempo completo, esto significa 445.663 efectivos (215.307 asalariados y 230.356 voluntarios). Los sueldos y salarios percibidos por el personal remunerado ascendían a 686.656 millones de pesetas. Durante la segunda mitad de la década de los noventa, los recursos humanos movilizados por el sector han crecido a una tasa anual media por encima del 5\%. De hecho, aunque algunas de las entidades que lo integran son centenarias, la mitad de ellas han sido creadas en esa década. Se estima que durante los dos años siguientes a la realización del estudio el sector seguirá creciendo a una tasa media superior al $7 \%$ anual. En todo caso, el futuro del sector «depende de la superación de importantes debilidades que pueden hipotecar, o cuando menos lastrar, su evolución y crecimiento, y frenar su proceso de consolidación» (Monzón, 2003: 94); entre esas debilidades destaca la ambigua relación que mantiene con las administraciones públicas: mientras que por una parte depende de ellas en términos financieros y reguladores, por otra desempeña el papel de brazo ejecutor de su política social. 
El interés creciente que ha conseguido despertar el trabajo voluntario en particular y el trabajo no remunerado en general cuestiona el concepto convencional de actividad económica, pues obliga a considerar como tal:

[...] las tareas que contribuyen a la reproducción social y al mantenimiento de la fuerza de trabajo y que no están entroncadas directamente con el mercado. [...] El problema esencial sigue siendo cómo medir y valorar el bienestar humano y cómo determinar quiénes contribuyen a él [...] lo cual plantea, a su vez, la validez de las premisas en que se basa el pensamiento establecido, en este caso las que asimilan el "trabajo» al tiempo dedicado al trabajo remunerado y al mercado (Benería, 1999: 330, 342, 343).

\section{El trabajo negro}

Como ya se ha dicho, en la otra economía también hay empleos. Es el criterio jurídico el que permite distinguir entre el empleo regular que se desenvuelve en la economía oficial y el empleo irregular propio de la otra economía. Habitualmente los estudiosos del trabajo irregular suelen obviar la economía criminal para orientar el punto de mira hacia las actividades productivas convencionales que se llevan a cabo infringiendo la legislación laboral o fiscal. En esta perspectiva, la OIT entiende por economía sumergida toda actividad profesional ejercida con fin lucrativo y de modo no ocasional, única o secundaria, que se lleva a cabo en el límite o al margen de las obligaciones jurídicas, reglamentarias o derivadas de un convenio (Comisión de las Comunidades Europeas, 1990: 127). Las comparaciones internacionales al respecto deben tener en cuenta que el marco legal que regula la actividad económica difiere según los países. Piénsese en la prostitución, en la edad mínima de acceso al mercado de trabajo o en el tratamiento normativo de los trabajadores ligados por vínculos familiares al titular de una unidad productiva.

Inspirándonos en Banyuls y otros (2002/2003: 79), podemos distinguir tres tipos básicos de empleo irregular:

1) El constituido por aquellas situaciones en que no se vulnera de manera significativa la legislación laboral, por lo que se mantienen esencialmente en el ámbito de la economía oficial a efectos de condiciones de trabajo y protección social. Es el caso del pago de complementos salariales en negro a trabajadores contratados formalmente, o la adscripción formal del trabajador a un empleo de categoría inferior al que de hecho desempeña, a fin de reducir las cotizaciones sociales. Estas irregularidades pueden ser relevantes en términos fiscales, pero no son significativas desde el punto de vista de las condiciones de trabajo.

2) El constituido por aquellas modalidades de trabajo remunerado cuya regulación legal es incompleta, inadecuada o sencillamente inexistente, de manera que se desenvuelven en un marco de alegalidad más que de ilegalidad. Es en buena medida el caso del servicio doméstico en España. Una normativa poco realista y la escasa consideración social de estas trabajadoras 
hace posible que no suelan estar dadas de alta en el Régimen Especial de la Seguridad Social de Empleados de Hogar. Sólo al empleador que tiene un sirviente en dedicación exclusiva y elevada puede exigírsele formalmente que asuma las cotizaciones sociales correspondientes; por lo general éstas corren por cuenta de la propia empleada, a cambio de lo cual recibe una protección que no justifica el esfuerzo. En estas circunstancias, no es sorprendente la modesta proporción de empleados de hogar dados de alta en la Seguridad Social respecto a la ocupación estimada por la EPA en este sector: un 48 por ciento en 1990 y un 38 por ciento en 1999 (Banyuls y otros, 2002/2003: 84-85). El recurso creciente a trabajadores inmigrantes, muchas veces no regularizados, por parte de las familias confiere una nueva dimensión a la problemática de este sector ocupacional.

3) El constituido por aquellas situaciones en que se vulnera significativa o totalmente la legislación laboral. Es el caso de los asalariados sin contrato, es decir el trabajo negro, definido por contraposición al trabajo blanco propio de la economía oficial.

Hay diversas modalidades de trabajo negro que pueden clasificarse en función del grado de voluntariedad con que el trabajador acepte la situación (Sanchis, 1988: 21). Aparecen así dos tipos extremos: los que no tienen más remedio que trabajar en negro como única vía de acceso a una renta de supervivencia y los que lo buscan por iniciativa propia, muchas veces para completar ingresos procedentes de otras fuentes; entre ambos, distintas combinaciones híbridas. Si en unos casos el trabajo negro será consecuencia de un acuerdo cómplice entre demanda y oferta, en otros será la demanda de trabajo la que imponga sus condiciones. El peso relativo de una u otra modalidad en las sociedades avanzadas tiene que ver con variables subjetivas ligadas a las motivaciones de los actores y con variables estructurales. El hecho de que la tasa de paro se cuadruplique según los países no es irrelevante. El trabajo negro no puede entenderse sin tener en cuenta el problema del enquistamiento del paro y del deterioro de las condiciones de trabajo y de vida al que se enfrentan las sociedades avanzadas con motivo de la crisis del empleo y del Estado de bienestar, que obliga a las unidades familiares a redefinir sus estrategias de acceso a rentas (Offe y otros, 1992).

La Unión Europea se ha ocupado de esta cuestión en varias ocasiones. En una comunicación de la Comisión, se señalan cuatro tipos básicos de trabajadores no declarados (Comisión Europea, 1998: 7):

1) Activos pluriempleados cuya ocupación principal se desenvuelve en la economía oficial. A juicio de la Comisión, éste es el tipo predominante de trabajo negro.

2) Individuos oficialmente inactivos (amas de casa, jubilados o prejubilados, estudiantes).

3) Parados, cuya propensión al trabajo negro depende de la cuantía del subsidio y del riesgo de perderlo, siendo la capacidad de resistencia a una ofer- 
ta de empleo no declarado directamente proporcional a la cuantía del subsidio.

4) Inmigrantes irregulares, que constituyen el tipo más vulnerable y son atraídos por la existencia de una bolsa significativa de empleos rechazados por la población autóctona.

Un estudio más reciente encargado por la Dirección General de Empleo y Asuntos Sociales de la Comisión Europea (Renooy y otros, 2004) señala en el mismo sentido que la participación en la economía informal está dominada por hombres cualificados, entre 25 y 45 años de edad, que tienen también empleos regulares. Frente a este grupo dominante, los otros (mujeres, estudiantes, parados) obtienen ingresos inferiores y trabajan más tiempo en empleos menos interesantes. Se apunta igualmente que el trabajo sumergido de las mujeres tiene un carácter más permanente que el de los hombres y que ellas (al contrario que los hombres) lo hacen más por «necesidad económica» que por ganar un poco más. Como veremos un poco más adelante, desde la perspectiva española esta tipología resulta sorprendente, ya que nuestro trabajador sumergido por excelencia es una mujer no dada de alta en la Seguridad Social que combina el empleo irregular con las labores domésticas, y la propensión de las mujeres a participar en la economía sumergida es mucho más alta que la de los hombres.

Curiosamente, en la tipología europea no se hace referencia explícita al caso de los parados no protegidos por el subsidio de desempleo u otro dispositivo similar. Es cierto que se enfatiza la insuficiencia de la protección antes que su generosidad como factor estimulante de la oferta de trabajo negro, pero no por ello deja de llamar la atención esta omisión. Quizás en muchos países miembros la mayoría de los parados disponen de alguna red formal de seguridad, pero no es éste el caso de los parados españoles. En 1978 la proporción de beneficiarios de algún tipo de prestación por desempleo respecto al paro estimado por la EPA era casi del 50 por ciento, y fue cayendo hasta casi el 30 por ciento en 1983. A partir de ese año crece, «alcanzando en 1988 un nivel similar al de diez años antes. Entre los años 1988 y 1991, la tasa de cobertura EPA siguió una tendencia alcista que se tradujo en un valor máximo para este último año del 66 por ciento. Desde entonces, la tasa ha experimentado una continua reducción hasta alcanzar el nivel del 37 por ciento en 1997» (Arango, 1999: 173).

Así pues, la oferta de trabajo negro está constituida por cierta diversidad de tipos sociales. El pluriempleado puede buscar primordialmente ingresos adicionales, pero también aquellas compensaciones expresivas o profesionales que no le proporciona el empleo blanco, aunque esté bien pagado. Otro tanto puede decirse del prejubilado, no necesariamente con problemas económicos pero sí con mucho tiempo disponible. Habrá estudiantes que sólo buscarán dinero de bolsillo; otros, los recursos necesarios para poder seguir estudiando. La mujer que se autodefine como ama de casa puede tener tras de sí todo tipo de motivaciones expresivas o instrumentales. La que está al frente de una uni- 
dad familiar es posible que no tenga otra opción en el mercado de trabajo. El parado sin protección buscará un puente hacia el empleo blanco. Y el mundo del empleo blanco pero infrapagado y precario debe ser también un excelente vivero de aspirantes a un segundo empleo negro. Finalmente, tampoco faltará el experto en cálculo racional del análisis económico ortodoxo especialmente dotado para obtener el máximo beneficio del sistema a cambio del mínimo esfuerzo.

Tres ideas generales pueden destacarse en relación con todo esto. Primero, no todo el trabajo negro es estadísticamente opaco. Por ejemplo, entre 1987 y 1997, aproximadamente un 5 por ciento de las mujeres y entre el 5 y el 10 por ciento de los varones que declararon a la EPA estar recibiendo prestaciones por desempleo, afirmaron al mismo tiempo que estaban trabajando (Toharia, 1998: 209 y s.). En consecuencia, aunque obviamente estaban incluidos en las estadísticas de paro registrado, a efectos EPA fueron contabilizados entre los activos ocupados. Segundo - y corolario de lo anterior- la existencia de cierta bolsa de trabajo negro tiene repercusiones más bien modestas sobre la estimación de desempleo oficial. Dado que la mayor parte del trabajo negro lo hacen individuos clasificados ya sea entre los ocupados o entre los inactivos, su registro estadístico se traducirá en un aumento de la tasa de actividad y en una reducción de la tasa de paro, pero no necesariamente en una caída significativa del número de desempleados. Es absolutamente falsa la idea, que pretende hacerse pasar por buena, de que el tipo dominante de trabajo negro es encarnado por un parado perceptor del subsidio de desempleo:

Aunque sean las denuncias de parados que se benefician de subsidios de desempleo y a la vez realizan una actividad remunerada las que retienen la atención y las críticas del público y los políticos [...] los casos de abusos flagrantes contra los fondos públicos [son] muy raros. [...] De hecho las repercusiones de la economía sumergida sobre el mercado de trabajo y la sociedad en general son más preocupantes que su carácter de fraude fiscal y administrativo, ya que [...] la cuantía de las pérdidas debida a ellos es mucho menor que la que suponen otros tipos de fraudes (Comisión de las Comunidades Europeas, 1990: 130).

Tercero, en otro tiempo los mundos del trabajo blanco y del trabajo negro eran dos realidades claramente diferenciadas; en la actualidad, con la desregulación creciente del mercado de trabajo, entre ambos se está consolidando una zona gris (la del trabajo blanco pero precario) que obliga a afinar los instrumentos de análisis, pues en ella se acumulan rasgos característicos tanto del trabajo blanco como del negro.

Trabajo negro hay en todas las economías avanzadas y en todos los sectores de actividad. No es necesario insistir en las dificultades que presenta su cuantificación y su traducción a empleos equivalentes a tiempo completo. La Comisión Europea considera que "por término medio, la importancia de la economía no declarada en la UE puede estimarse entre un $7 \%$ y un $16 \%$ del PIB de la UE, lo que equivaldría a entre 10 y 28 millones de unidades de tra- 
bajo, o entre el 7\% y el 19\% del volumen total de empleo declarado» (Comisión Europea, 1998: 5). En cambio, todos los estudios coinciden en señalar que el problema afecta sobre todo a los países de Europa meridional. Ejemplos clásicos de trabajo negro son - entre otros - la industria del calzado en el País Valenciano, la fabricación de guantes en Nápoles y los talleres de confección ilegales que emplean inmigrantes del Tercer Mundo en la región parisina (Sanchis, 1984; Comisión de las Comunidades Europeas, 1990: 128; Ybarra y otros, 2001).

El intento más ambicioso de conocer el volumen y la composición del trabajo irregular en España se llevó a cabo en 1985. Fue auspiciado por la Administración central del Estado y consistió en una encuesta sobre uso del tiempo en el marco de la cual se trataba de averiguar la situación del entrevistado en el mercado laboral y su vinculación con el sistema de la Seguridad Social (VV. AA., 1986). Los resultados de la encuesta fueron objeto posteriormente de análisis más detallados (Muro y otros, 1988; Moltó y otros, 1991). El criterio de distinción entre trabajo regular e irregular se basó en la relación con el sistema de la Seguridad Social, y se definieron cinco situaciones de irregularidad:

1) Trabajadores que no están dados de alta en la Seguridad Social.

2) Trabajadores dados de alta que no cotizan.

3) Asalariados que cotizan como autónomos.

4) Autónomos que cotizan como asalariados.

5) Perceptores del seguro de desempleo ocupados.

A finales de 1985 en el mercado de trabajo español había 12.260 .000 ocupados en sentido amplio. El 65,8 por ciento estaban declarados a la Seguridad Social y no presentaban anomalías respecto a la misma. El 18,4 por ciento presentaban irregularidades respecto a la Seguridad Social. El 15,8 por ciento restante se encontraban en una situación indefinida, en el sentido de que sus obligaciones al respecto no estaban claramente determinadas. Era el caso de casi un millón de trabajadores (ayudas) familiares o de los 820.000 entrevistados que no explicitaron su situación profesional con la suficiente precisión o que no facilitaron información de ningún tipo sobre sus relaciones con la Seguridad Social; un total de 1.934 .000 individuos que se decidió no incluir en el análisis. Así pues, sobre 10.326.000 ocupados analizados los trabajadores irregulares eran el 21,9 por ciento (cuadro 1).

En función del tipo de irregularidad, los 2.258.000 ocupados irregulares se distribuían de la forma siguiente:

1) Ocupados no declarados (sin cartilla de la Seguridad Social): 65,6 por ciento.

2) Titulares de cartilla que no cotizan: 15,2 por ciento.

3) Asalariados que cotizan como autónomos: 8,8 por ciento.

4) Autónomos que cotizan como asalariados: 5,1 por ciento.

5) Perceptores del seguro de desempleo ocupados: 5,2 por ciento. 
Cuadro 1. Datos básicos del trabajo irregular. España, 1985.

Ocupados analizados

Ocupados irregulares

Oc. sent. estricto irregulares

Índice irregularidad global

Hombres

Mujeres

Asalariados

Autónomos

Trabajadores a domicilio

Ocupados irregulares

Sin cartilla S. S.

Con cartilla sin cotizar

Asalariados como autón. y viceversa

Perceptores del subsidio de desempleo

Perceptores del subsidio de desempleo

(más de la mitad en Extremadura y Andalucía)

Fuente: VV. AA., 1986 (elaboración propia).
10.326 .000

2.258 .000

1.673 .000

$21,9 \%$

$16 \%$

$36 \%$

$19 \%$

$30,4 \%$

$43,8 \%$

$2.258 .000(100)$

$65,6 \%$

$15,2 \%$

$13,9 \%$

$5,2 \%$

118.000

(sólo 54.000 oc. sent. estricto)

Así pues, el tipo de irregularidad más significativo es el primero, al acoger a dos de cada tres ocupados irregulares. Dentro del segundo grupo están los jubilados y pensionistas. En el tercer grupo se encuentran los trabajadores que se autodefinen como asalariados a los que la empresa les obliga a darse de alta como autónomos si quieren acceder al empleo. Procediendo así la empresa, se ahorra la cuota de la Seguridad Social y reduce virtualmente a cero el coste del despido. Los autónomos que cotizan como asalariados suelen hacerlo para darse de alta en un régimen más barato, como es el de los asalariados agrícolas. Esto les permite, además, acceder a los dispositivos de protección específicos de los jornaleros eventuales. Prácticamente la mitad de los asalariados que cotizan como autónomos y de los autónomos que cotizan como asalariados se concentran en la agricultura y la construcción.

Por lo que se refiere a los 118.000 perceptores del seguro de desempleo, que como se sabe es el tipo dominante en la imagen social del trabajo negro, cabe hacer algunas precisiones. Ante todo, es lógico pensar que ésta puede ser la situación de una parte de la población que se optó por no analizar (o que no se dejó analizar). Sin embargo, el sesgo alcista en el peso del grupo que provocaría la consideración de este hecho queda lastrado por la circunstancia de que algunos de los definidos en la encuesta como ocupados pueden tener legítimo derecho a cobrar el desempleo, por lo que no están en situación de irregularidad (VV. AA., 1986: 87). Además, este tipo de irregularidad es mucho más 
frecuente entre los ocupados marginales que entre los ocupados en sentido estricto. Mientras de los ocupados estrictos en situación irregular (1.673.000) sólo 54.000 están cobrando el seguro de desempleo (3,2 por ciento), entre los ocupados marginales la proporción asciende al 10,9 por ciento. Esto «sugiere que muchos ocupados marginales entran en el mercado de trabajo regular para trabajar por un tiempo determinado y tener acceso al seguro de desempleo y una vez terminado su contrato simultanean la percepción del seguro de paro con un trabajo en el mercado irregular. [Lo cual debe interpretarse] con cierta cautela, ya que dentro del colectivo de ocupados marginales se pueden encontrar determinados trabajadores cuya cotización a la Seguridad Social sea difícilmente exigible desde un punto de vista jurídico por lo que el índice de irregularidad estimado para dicho grupo [...] constituye más un indicador sociológico que un indicador de fraude fiscal» (VV. AA., 1986: 98). Es también significativo que este tipo de irregularidad sea mucho más frecuente en la agricultura y la construcción, lo que debe estar relacionado con la estacionalidad típica de ambos sectores. De cada cien ocupados irregulares en la agricultura, 7,3 cobran el seguro de desempleo (35.000); situación en que se encuentran 18,9 de cada cien ocupados irregulares en la construcción (28.000). Finalmente, hay que destacar asimismo que el tamaño relativo de este grupo es mucho mayor en Extremadura y Andalucía, comunidades en las que se concentra el 54,4 por ciento de los ocupados perceptores del subsidio de desempleo: en estas regiones, de cada cien ocupados irregulares, 15,3 y 12,1 respectivamente incurren en este tipo de irregularidad.

En todos los sectores de la economía española hay trabajo irregular. Las ramas de actividad que se desvían sensiblemente por encima de la media son: servicios domésticos $(60,4 \%)$, confección $(42,9 \%)$, calzado $(37,8 \%)$, cuero $(32 \%)$, servicios personales $(34,5 \%)$ y agricultura $(30,9 \%)$. En general, el índice de irregularidad está inversamente relacionado con el tamaño de la empresa: allí donde la pequeña empresa es más frecuente, los niveles de irregularidad son más elevados. También es significativa la distinción entre asalariados y autónomos: el índice de irregularidad de los asalariados es el 19\% y el de los autónomos el 30,4\%. Otras características del mercado de trabajo irregular son (siempre en términos relativos): mayor proporción de empleo juvenil, menor nivel educativo y cualificación profesional, mayor rotación en el empleo, menores ingresos y mayor presencia de ocupados marginales y de mujeres. Sólo el $12 \%$ de los ocupados cabezas de familia trabajan en el mercado irregular frente al 38,3\% de los ocupados sin responsabilidades familiares. Mientras el $36 \%$ de las mujeres ocupadas se encuentran en el mercado irregular, la proporción correspondiente a los varones es del 16\%. Así, las mujeres son casi la mitad $(48,4 \%)$ de los ocupados en el mercado irregular.

La participación relativa de hombres y mujeres en el trabajo irregular merece un comentario específico, ya que no guarda proporción con la distribución por sexos de la muestra (más del doble de hombres ocupados analizados) ni con las tasas de actividad oficiales. Hay casi tantos ocupados irregulares mujeres como hombres (1.093.000 frente a 1.165.000), pero su distribución 
entre las cinco situaciones de irregularidad definidas registra diferencias significativas. Así, «los ocupados sin estar dados de alta en la Seguridad Social son relativamente más frecuentes entre las mujeres, ya que suponen el 81,6\% del total de las irregularidades en que incurre este colectivo, mientras que entre los varones este porcentaje desciende a un 50,6\%. Ello hace que, en el resto de irregularidades consideradas, los porcentajes de las mujeres sean siempre más bajos que los correspondientes a los varones» (VV. AA., 1986: 135). El mayor peso relativo de mujeres y jóvenes explica la escasa presencia de trabajadores con responsabilidades familiares en el mercado irregular. Por otra parte, la abrumadora concentración de mujeres y jóvenes $(83,9 \%)$ en el primer tipo de irregularidad se ve facilitada por la posibilidad de ser incluidos en la cartilla del cabeza de familia, alegando ante la Seguridad Social que son inactivos.

Mención específica hay que hacer asimismo al trabajo a domicilio, donde la presencia femenina suele ser dominante. La encuesta detecta 957.000 trabajadores a domicilio, incluye a 710.000 en la población analizada y clasifica a 311.000 entre los ocupados irregulares. Por tanto, frente al índice de irregularidad global del 21,9\%, el de los trabajadores a domicilio asciende al 43,8\%. Por último, las situaciones de irregularidad son mucho más frecuentes entre los ocupados marginales que entre los estrictos, ya que los índices de irregularidad son, respectivamente, el 71,9\% y el 17,6\%. No obstante, «la fuerza de trabajo marginal ocupada sólo constituye el $25,9 \%$ de la población irregular $\mathrm{y}$, sin lugar a dudas, los 1.673 mil irregulares estimados en el conjunto de los ocupados estrictos indican claramente la gravedad del problema de la economía sumergida en la sociedad española» (VV. AA., 1986: 100, cursiva nuestra).

A la vista de estos datos, pueden sugerirse algunas conclusiones en cuanto a la estructura social del trabajo irregular en España, siempre en el supuesto de que la situación no haya cambiado sustancialmente desde mediados de los años ochenta (cuadro 2). En primer lugar, la representación social dominante del trabajo negro (el realizado por un parado protegido) no se corresponde con la realidad. En segundo lugar, mientras que a juicio de la Comisión Europea el tipo predominante de trabajo no declarado es el realizado como segunda actividad por hombres ocupados regulares, no parece ser éste el caso

Cuadro 2. Tipos sociales básicos de trabajadores irregulares. España, 1985.

1) Mujeres sin cartilla $S$. S.

2) Hombres jóvenes (14-24) sin cartilla S. S.

$892.000 \quad(39,5 \%)$

3) Hombres y mujeres con cartilla sin cotizar

$365.000 \quad(16,2 \%)$

4) Hombres adultos sin cartilla S. S.

$344.000 \quad(15,2 \%)$

Otros irregulares

$225.000(10 \%)$

$(19,1 \%)$

Nota: es posible que esta tipología básica siga vigente en la actualidad salvo en lo que se refiere a la necesidad de incorporar un nuevo tipo constituido por los inmigrantes irregulares.

Fuente: VV. AA., 1986 (elaboración propia). 
de la economía española. Ciertamente, en la encuesta no se explora esta posibilidad. Sólo tratan de investigar el pluriempleo de la población ocupada en lo que llaman un puesto de trabajo "objetivamente estable», sin precisar si éste es blanco o negro ni si el segundo empleo es negro o blanco. Estiman 9.917.000 ocupados no ocasionales, el 8,8 por ciento de los cuales (871.000) tendrían un segundo empleo. Dentro de este colectivo se encuentran desde los 286.000 pluriocupados cuyo segundo trabajo consiste en colaborar en el negocio familiar, que por definición no es trabajo irregular, hasta los 42.000 ocupados que hacen su segundo trabajo en el propio domicilio, modalidad que, como sabemos, presenta un índice de irregularidad elevado. Lo que se pretende apuntar es que, independientemente de la hipótesis que se formule acerca del carácter más o menos negro de la segunda actividad, el trabajador sumergido típico de la economía española es:

1) Una mujer no dada de alta en la Seguridad Social (892.000 personas, $39,5 \%)$. Puede suponerse que la gran mayoría de estas mujeres están incluidas en la cartilla de la Seguridad Social de un cabeza de familia. Es posible que muchas de ellas estén clasificadas en la EPA como inactivas, y probablemente se autodefinen como amas de casa. Si les agregamos los 365.000 hombres de 14-24 años (16,2\%) igualmente no dados de alta en la Seguridad Social, podemos redefinir el tipo dominante de trabajador irregular español (55,7\% de los casos) como un individuo cuyos ingresos laborales no son la fuente principal de rentas de la unidad familiar de la que forma parte y sobre el cual se ejerce menos presión social que sobre el hombre adulto para que se integre plenamente en el mercado de trabajo regular. Una parte probablemente minoritaria de estos individuos y sus familias pueden vivir en situación de grave precariedad económica; para el resto, la opción por el mercado irregular incluye en cierto sentido un componente de voluntariedad. Es la importancia numérica de este tipo dominante de trabajador no declarado lo que explica la tolerancia social hacia la economía sumergida, pues, a fin de cuentas, trabajadores irregulares y regulares duermen bajo el mismo techo y muchas veces en la misma cama, hecho que reclama asimismo la necesidad de tener en cuenta las estrategias familiares de acceso a rentas para entender el trabajo negro.

2) A continuación, pero a mucha distancia, hombres y mujeres dados de alta en la Seguridad Social que no cotizan (344.000 individuos, 15,2\%). Se supone que la mayoría de ellos son jubilados y pensionistas, por lo que llama la atención que sólo 98.000 superen la edad de 54 años; más de dos de cada tres son hombres.

3) Hombres adultos no dados de alta en la Seguridad Social (225.000 individuos, $10 \%)$. Reiterando las reflexiones realizadas a propósito del tipo dominante, podemos intuir que en este caso se trata de individuos identificados con la posición social del parado, con graves dificultades de acceso al mercado regular, no protegidos por el subsidio de desempleo y cuyas unidades familiares sufren grave precariedad económica. 
Como la encuesta de 1985 no ha vuelto a ser aplicada, no podemos saber a ciencia cierta si la estructura social del trabajo irregular ha experimentado modificaciones sustanciales desde entonces. En todo caso, puede afirmarse que a esta tipología básica se habría incorporado recientemente otro grupo social:

4) Inmigrantes sin papeles. La comparación de los datos padronales correspondientes a 2001 con los registros oficiales de extranjería permite deducir que en España viven en esa fecha unos 500.000 inmigrantes en situación irregular. Datos más recientes señalan que la brecha entre empadronados y regularizados crece día a día, de manera que no es aventurado suponer que durante el tiempo transcurrido desde 2001 hasta el momento en que se lean estas líneas la bolsa de inmigración irregular al menos se habrá duplicado. Cabe sospechar que la gran mayoría trabaja en la economía sumergida.

Junto a la aparición de este último tipo, puede conjeturarse otro cambio en la estructura del trabajo irregular, esta vez relativo a la configuración social del tipo dominante. Si aceptamos que sobre el mercado de trabajo regular se vislumbran nubarrones de inseguridad —al menos en la percepción subjetiva de los ocupados- y tenemos en cuenta el hecho cierto de que la sociedad española está conociendo un proceso acelerado de redefinición de los roles femeninos, el resultado habría sido la reducción paulatina de las mujeres autodefinidas como amas de casa y la menor significatividad del componente de «voluntariedad» en la decisión de acceder al mercado irregular.

Tanto la tipología de la UE como la española son estilizaciones de un hecho social más complejo. De ellas no puede deducirse que la economía oficial y la otra son dos mundos paralelos, pues forman parte de un mismo sistema integrado que, eso sí, tiene un pie en lo formal y otro en lo informal. «Hay tantas formas de otra economía como formas de economía convencional, y ambas se encuentran ligadas hasta tal punto que éstas ya no son concebibles sin aquéllas. En consecuencia, formas de otra economía encontramos por doquier, y no pueden ser analizadas sin tener en cuenta sus íntimas vinculaciones con las formas de economía convencional en que se insertan» (Sanchis, 1988: 9). Esto tiene al menos dos implicaciones. La primera está relacionada con los intentos de precisar el tamaño de la economía sumergida, de lo que nos ocuparemos en la sección siguiente. La cuantificación de la economía sumergida suele asumir al menos implícitamente el supuesto de que es alternativa a la economía oficial, cuando muchas veces desempeña funciones complementarias. Así, la visión de que en las sociedades avanzadas la economía informal fue tendencialmente integrada en la formal durante las tres décadas posteriores a la Segunda Guerra Mundial para después comenzar el proceso contrario, y por tanto de que está creciendo a su costa desde entonces, puede hacer olvidar que «la trayectoria del desarrollo económico no sigue universalmente el sendero de la formalización o informalización, sino que está mucho más diversificada de lo que hasta ahora se ha considerado. [...] La magnitud y el crecimiento o reducción del empleo informal varía según localidades, regiones y naciones. [...] La 
cambiante configuración socioespacial del nivel y naturaleza del empleo informal es el resultado de la manera como condiciones económicas, sociales, institucionales y ambientales se combinan en múltiples "cócteles" en diferentes lugares para producir resultados locales específicos. La consecuencia es que, en un momento dado, no hay un proceso de informalización universal a lo largo de las economías avanzadas, sino más bien procesos diferentes en lugares diferentes» (Williams y Windebank, 1998: 26, 46). Dicho en otras palabras, analizar la economía sumergida en clave dualista puede no ser el enfoque idóneo. En términos similares, y ésta es la segunda implicación, «el empleo informal no es simplemente una estrategia de supervivencia de [ciertos colectivos] marginalizados [como parados, minorías étnicas o inmigrantes], sino que más bien hay un mercado de trabajo informal heterogéneo con su propia jerarquía, que reproduce las divisiones socioespaciales prevalecientes en el mercado de trabajo formal» (Williams y Windebank, 1998: 26). Es decir, no reduzcamos la economía sumergida a una forma periférica de empleo reservada a grupos marginales, ya que hay tantos tipos de trabajo irregular como de regular y en él participa una extensa gama de individuos por una amplia variedad de razones. No hay que confundir la precariedad económica que puede caracterizar a muchos empleos irregulares con la precariedad social de quienes los ocupan. Ésta depende más de las condiciones familiares que de las laborales. El empleo irregular puede ser, en unos casos, una etapa transitoria hacia el mercado formal; en otros, una trampa de la que no es fácil escapar.

\section{El tamaño de la economía sumergida}

El interés por conocer las dimensiones y características del trabajo irregular responde a varios tipos de preocupaciones. Los gobiernos buscan sobre todo acotar la bolsa de fraude fiscal y en las prestaciones sociales, así como la inmigración ilegal, pero también evitar el sesgo que podría introducir un conocimiento deficiente de la realidad en las decisiones de política económica. Las organizaciones empresariales suelen referirse a la competencia desleal que soportan las unidades productivas que respetan la legislación fiscal y laboral y a la presencia excesiva del Estado en la economía. A los sindicatos les preocupa especialmente la dinámica que pueda existir entre lo que ocurre en el ámbito del trabajo en el que suelen estar presentes institucionalmente y lo que ocurre en aquel otro que casi por definición escapa a su control. Es decir, hasta qué punto las posiciones alcanzadas en el ámbito del trabajo blanco no son burladas mediante la expansión del trabajo negro. Pero la existencia de otra economía les obliga también a replantearse sus funciones en la sociedad posindustrial, pues de alguna manera pone en cuestión su pretensión de representar y defender los intereses de todos los trabajadores. En este sentido, tienen que hacer frente a dos hechos particularmente problemáticos: 1) la representación y articulación de intereses de aquellos ocupados en cuya identidad social la actividad laboral no ocupa una posición dominante, circunstancia que puede contribuir a explicar el trabajo negro voluntario; 2) la necesidad cada vez más 
evidente de potenciar la conciliación entre vida laboral y trabajo doméstico, que poco a poco va afectando también a los hombres. Todas estas preocupaciones, junto a otras de carácter más teórico, han estado también en el punto de mira de los estudiosos de la economía y de la sociedad. En función de los intereses investigadores, la cuantificación de la otra economía será un objetivo más o menos importante; en todo caso, su tamaño es un dato cuya relevancia no puede ser desdeñada.

Schneider y Enste han revisado los diferentes métodos de cuantificación y llevado a cabo sus propias estimaciones. Consideran economía oculta «aquellas actividades legales creadoras de valor añadido que no están fiscalizadas o registradas, la mayor parte de las cuales pueden ser clasificadas como trabajo "negro" o clandestino» (Schneider y Enste, 2000: 79). Excluyen pues explícitamente el trabajo no remunerado y las actividades delictivas. Todos los métodos tienen ventajas y limitaciones, no habiendo ninguno mejor o comúnmente aceptado, y suelen dar resultados muy diferentes. Por tanto — advierten-, hay que ser muy cuidadoso al interpretar el tamaño de la economía oculta en un país utilizando sólo un método, aunque el recurso a varios de ellos permite hacerse una idea en cuanto a su importancia y, sobre todo, evolución. Schneider y Enste estudian varias docenas de países, encontrando que en todos ellos y según todos los sistemas de estimación la economía sumergida ha alcanzado un gran tamaño y ha crecido durante los años noventa. "Aunque los diferentes métodos proporcionan un abanico de estimaciones más bien amplio, el resultado común es que en la mayoría de los países en transición y en todos los de la OCDE estudiados la economía oculta ha estado creciendo durante la década pasada. Lo mismo puede decirse respecto al mercado de trabajo de la economía oculta» (Schneider y Enste, 2000: 107). Siempre según estos autores, en 19971998, en la Unión Europea al menos 20 millones de trabajadores y alrededor de 35 en el conjunto de la OCDE trabajaban en la economía no oficial.

Dos procedimientos de estimación indirectos aplicados con frecuencia son el basado en el consumo de electricidad y el que utiliza como indicador la demanda de dinero líquido. Teniendo en cuenta que la demanda de energía eléctrica es función del nivel de actividad económica, se establece la relación entre ambas magnitudes a lo largo del tiempo para atribuir al crecimiento de la economía sumergida aquella parte del incremento del consumo eléctrico que no puede atribuirse al incremento del PIB oficialmente medido. En términos similares, partiendo de la hipótesis de que en la economía sumergida los pagos se efectúan en metálico, se calcula la relación entre el nivel de actividad económica y la cantidad de efectivo en un año base, y la parte del aumento de la demanda de dinero no explicada por el aumento del PIB oficial al final del período considerado se atribuye igualmente al crecimiento de la economía sumergida. Combinando ambos métodos, Schneider y Enste estiman el tamaño medio de la economía oculta como porcentaje del PIB en diversos países y años. En 1990-1993, los niveles máximos se alcanzan en algunas economías africanas y asiáticas, con valores en torno al 70 por ciento. En Latinoamérica se distinguen dos grupos de países: aquellos donde la economía sumergida oscila 
entre el 25-35 por ciento y aquellos otros en que oscila entre el 40-60 por ciento. En siete de las catorce antiguas economías socialistas consideradas, el tamaño va del 20 al 28 por ciento del PIB (es el caso de Rusia), en tres queda por debajo (9-16 por ciento) y en las otras cuatro lo supera (28-43 por ciento). Los países de la OCDE pueden agruparse en tres categorías. En el grupo de cabeza (24-30 por ciento) se encuentran entre otros los mediterráneos; en el intermedio (13-23 por ciento), países como Alemania, Francia, Gran Bretaña y Suecia; en la cola (8-10 por ciento), Austria, Estados Unidos, Japón y Suiza. En el cuadro 3 se reproducen las estimaciones más recientes de los autores para veinte países de la OCDE basadas en el método de la demanda de dinero efectivo.

Alañón y Gómez han diseñado un método de estimación de la economía sumergida española basado en la demanda de efectivo. Su objetivo es «evaluar la parcela de la economía sumergida que corresponde a los hechos económicos ocultos de carácter fiscal» (Alañón y Gómez, 2003: 8); es decir, aquellos ingresos realizados en efectivo por razones fiscales que permanecen al margen de la Contabilidad Nacional. Por tanto, excluyen las actividades ilegales y el trabajo no remunerado. En coherencia con esta definición, se trata

Cuadro 3. Tamaño de la economía oculta en veinte países desarrollados como porcentaje del PIB.

\begin{tabular}{lcc}
\hline País & Promedio 1994-1995 & Promedio 1996-1997 \\
\hline Alemania & 13,5 & 14,8 \\
Australia & 13,8 & 13,9 \\
Austria & 7,0 & 8,6 \\
Bélgica & 21,5 & 22,2 \\
Canadá & 14,8 & 14,9 \\
Dinamarca & 17,8 & 18,2 \\
España & 22,4 & 23,0 \\
Estados Unidos & 9,2 & 8,8 \\
Francia & 14,5 & 14,8 \\
Gran Bretaña & 12,5 & 13,0 \\
Grecia & 29,6 & 30,1 \\
Holanda & 13,7 & 13,8 \\
Irlanda & 15,4 & 16,0 \\
Italia & 26,0 & 27,2 \\
Japón & 10,6 & 11,3 \\
Noruega & 18,2 & 19,4 \\
Nueva Zelanda & 11,3 & - \\
Portugal & 22,1 & 22,8 \\
Suecia & 18,6 & 19,5 \\
Suiza & 6,7 & 7,8 \\
\hline Promedio & 16,0 & 16,9
\end{tabular}

Fuente: Schneider y Enste, 2000: 104. 
de medir la economía sumergida generada por la presión fiscal global. Tras formular una función de demanda de efectivo para toda la economía española (legal y sumergida), obtienen una expresión que les permite cuantificar el tamaño de la economía sumergida respecto a la oficial y finalmente tanto las cifras absolutas como la variación anual de la economía sumergida. En el cuadro 4 se reproducen los resultados para el período 1980-2000. El valor añadido bruto (VAB) sumergido a precios constantes ascendía en 1980 a 4.271.270,1 millones de pesetas, cantidad equivalente al 15,5 por ciento del VAB legal. En 2000 el VAB sumergido a precios constantes ascendía a 9.779.243,6 millones de pesetas, cantidad equivalente al 20,9 por ciento del VAB legal. Como se ve, la economía sumergida española crece lentamente durante todo el período.

Entre las causas de la evolución al alza de la economía sumergida, Schneider y Enste enfatizan las que suele aducir el pensamiento económico ortodoxo, como son el crecimiento de la presión fiscal y de las cargas sociales y el aumento de la regulación de la actividad económica por parte del Estado, particularmente en lo que se refiere a la normativa laboral. No obstante, señalan también la decadencia de las virtudes cívicas y de la lealtad hacia las instituciones públicas combinada con el debilitamiento de la moral fiscal, pues "la economía oculta puede ser vista como un indicador de un déficit de legitimidad del orden social actual y de las normas que regulan las actividades económicas» (Schneider y Enste, 2000: 108). Si se acepta que la moral fiscal guarda alguna relación con la percepción ciudadana de la equidad del sistema impositivo, puede hacerse una reflexión adicional relativa al caso español. Según los sondeos de opinión al respecto que lleva a cabo el Centro de Investigaciones Sociológicas (CIS) desde 1985, en la actualidad tres de cada cuatro españoles consideran que no pagan más impuestos quienes más tienen y aproximadamente cuatro de

Cuadro 4. Economía sumergida de origen fiscal en España

\begin{tabular}{lclc}
\hline Año & \% VAB sum./leg. & Año & \% VAB sum./leg. \\
\hline 1980 & 15,5 & 1991 & 19,9 \\
1981 & 16,7 & 1992 & 19,4 \\
1982 & 16,3 & 1993 & 20,1 \\
1983 & 16,5 & 1994 & 20,2 \\
1984 & 16,7 & 1995 & 20,1 \\
1985 & 17,2 & 1996 & 20,0 \\
1986 & 18,7 & 1997 & 20,1 \\
1987 & 18,5 & 1998 & 21,2 \\
1988 & 18,4 & 1999 & 20,7 \\
1989 & 18,9 & 2000 & 20,9 \\
1990 & 19,8 & & \\
\hline
\end{tabular}

Fuente: Alañón y Gómez, 2003: 15. 
cada cinco sostienen que hay mucho fraude fiscal, opinión que no se ha modificado sustancialmente durante los últimos veinte años. El veredicto correspondiente sobre la equidad del sistema fiscal español no parece que pueda perjudicar al desarrollo de la economía oculta.

Sólo una razón podría inducir a pensar que la bolsa de trabajo irregular en la economía española sea menos voluminosa ahora que hace dos décadas: el hecho de que las sucesivas reformas del mercado laboral hayan podido reducir la diferencia de coste entre el trabajo blanco y el trabajo negro y, por tanto, la propensión de las unidades productivas a recurrir a éste último. Aun así, hay que temer que los posibles efectos beneficiosos del blanqueamiento de una parte del trabajo negro pueden haberse visto contrarrestados por un empeoramiento de las condiciones de trabajo en el mercado oficial. Hace ya demasiados años que cada jornada de trabajo se salda con la muerte de tres trabajadores víctimas de un accidente laboral. En el mismo sentido cabe interpretar el hecho de que la amplitud de nuestra zona gris (donde se encuentra el trabajo asalariado temporal) no tenga parangón con ningún otro país de la UE. En todo caso, son más los indicios de que la expansión de la economía sumergida habría hinchado la bolsa de trabajo irregular. La tasa de paro sigue siendo la más alta de la UE; la presión de las mujeres para acceder al trabajo remunerado sigue aumentando mientras las políticas de ayuda a la familia siguen bajo mínimos. En los sectores manufactureros intensivos en trabajo, es cada vez mayor la competencia de los nuevos países industrializados, situación que la incorporación a la UE de las antiguas economías socialistas sólo puede agravar. Como la respuesta a estos retos no está siendo un aumento a la altura de las circunstancias del gasto en $\mathrm{I}+\mathrm{D}$ ni por parte del Estado ni por parte de las empresas, sólo cabe sospechar que la bolsa de trabajo irregular se mantiene cuando menos estable. Al fin y al cabo, por mucho que avance el proceso de desregulación de las relaciones laborales, el trabajo negro siempre será más flexible y más barato que el blanco. Si el riesgo de utilizarlo sigue siendo mínimo, dada la tolerancia social al respecto y la falta de medios que caracteriza tradicionalmente a la Inspección de Trabajo, durante los próximos años seguiremos teniendo mucho trabajo irregular

\section{Dos reflexiones finales}

1. Durante los últimos veinte años la economía sumergida no ha dejado de atraer la atención de los estudiosos españoles. Sin embargo, tanto en el discurso gubernamental como en los medios de comunicación, el tema parece haber perdido relevancia. En estas circunstancias, hay que formularse inevitablemente una pregunta. ¿Por qué en la actualidad el interés por la otra economía es aparentemente menor que durante la década de los ochenta? Si la encuesta llevada a cabo en 1985 desde el CIS (Presidencia del Gobierno) confirmó que en España había una bolsa muy importante de trabajo negro, y todo induce a pensar que la situación no ha mejorado desde entonces, ¿por qué no ha sido replicada periódicamente de manera que pudiera seguirse la 
evolución del problema? Quizás no sea descabellado responder que se ha preferido mirar hacia otro lado. Las declaraciones por parte de las organizaciones empresariales en cuanto a la competencia desleal es posible que contengan cierta dosis de retórica. Los sindicatos han debido experimentar en carne propia las dificultades que entraña intentar mantener una posición radical ante el problema. Da la impresión que, salvo en casos dramáticos, de las condenas contundentes típicas de hace unos años se ha pasado a intentar elaborar estrategias más articuladas en la convicción, si no de que se enfrentan a una especie de maldición bíblica, de que denunciar el trabajo negro sirve de poco mientras no haya alternativas inmediatas de trabajo blanco. Pero es la inhibición de la Administración lo que más llama la atención. Son muy pocos los países en los que se han hecho estudios sobre el trabajo irregular basados en encuestas, y creo no equivocarme si afirmo que en ningún otro país de la UE se ha hecho nunca una encuesta tan ambiciosa, a una muestra tan amplia de la población, dedicada específicamente al tema, como la que se hizo en España. Es cierto que había buenas razones para ello, pero uno no puede dejar de sospechar que entre los objetivos que animaron aquella encuesta, en una época en que el desempleo llevaba varios años creciendo, estaba el de quitar hierro al problema del paro alegando que la EPA no lo medía bien. Como el resultado fue que la EPA española no era significativamente peor que la que se hace en otros países y ni entonces ni ahora el pleno empleo ha sido el primer objetivo de la política económica, probablemente el trabajo negro ha pasado a ser considerado un mal menor, dado que la alternativa es el paro. En cualquier circunstancia, todo parece indicar que la política de «apagón estadístico» desarrollada durante los ocho años de gobierno del Partido Popular tenía, entre otros objetivos, el de conseguir que la economía sumergida continuara permaneciendo efectivamente oculta. Sólo así se explica que en el informe de 2004 de la Comisión Europea no aparezcan datos sobre España.

Sin embargo, el trabajo negro sigue siendo un tema relevante no sólo para los estudiosos: afecta a las condiciones de trabajo y de vida, a los ingresos de la Seguridad Social, a la sostenibilidad del sistema de pensiones. Por tanto, no estaría de más que la Administración, veinte años después, se planteara la posibilidad de replicar la encuesta de 1985 . Alternativamente, al menos podría introducir una pregunta al respecto en alguna de sus encuestas; por ejemplo en la de calidad de vida en el trabajo. En ésta se pregunta sobre el tipo de contrato de los asalariados ("¿Cómo es su contrato o relación laboral?»), pero las posibilidades de respuesta se limitan a las diversas modalidades de vinculación indefinida o temporal. Obsérvese que la pregunta está formulada con la suficiente ambigüedad para permitir una respuesta que puede referirse tanto a una vinculación formal (contrato) como de hecho entre dador y tomador de trabajo. Como todo asalariado, tiene inevitablemente algún tipo de «relación laboral» con su empleador (sólo el 1,1\% de los respondedores no sabe/no contesta a la pregunta), nos quedamos sin saber si tal relación laboral está o no formalizada en un contrato. Una pregunta adicional sobre la relación con la Seguridad Social resolvería el problema y se convertiría en un indicador valio- 
so del volumen y la evolución del trabajo negro. Huelga precisar que esta pregunta no debería hacerse sólo a los asalariados, ya que son los ocupados por cuenta propia quienes muestran tradicionalmente mayor propensión a instalarse en el mercado irregular.

2. Si entendemos por trabajo toda actividad humana orientada a la obtención de bienes y servicios generadores de bienestar, inspirándonos en Esping-Andersen (2000), podemos convenir que en las sociedades avanzadas tal actividad se desarrolla fundamentalmente en el seno de tres instituciones sociales: la familia, el mercado y el Estado. El esfuerzo relativo de cada una de estas instituciones en el desempeño de sus funciones determina cierto reparto de la carga global de trabajo entre familia (trabajo no remunerado), mercado y Estado (empleos). A su vez — y en función también de otros factores - los empleos aparecerán distribuidos entre regulares e irregulares. Supongamos, para simplificar el razonamiento, que el mercado sólo atiende la producción económica; la familia, sólo la reproducción social, y que el Estado interviene en los dos ámbitos. Pues bien, son las peculiaridades del modelo capitalista español y de su régimen de bienestar correspondiente lo que explica el gran tamaño relativo que tiene la bolsa de empleo irregular en España y lo que obliga a la familia española a reforzar su papel en la producción de un bienestar que el mercado no puede y el Estado no quiere suministrar. El mercado porque la demanda es en buena medida insolvente y el Estado porque llevamos una década alejándonos de la media europea en gasto social (Navarro y Quiroga, 2003). El ámbito de la producción económica no puede funcionar sin el soporte que le proporciona el ámbito de la reproducción social, pero, al contrario de cuanto ocurre en otras sociedades avanzadas, aquí éste es sostenido mucho más por la familia y mucho menos por el Estado.

Si son las deficiencias de nuestro sistema productivo las que estimulan la mayor propensión con que los españoles acceden al ámbito de la producción económica a través del empleo irregular, es el raquitismo de nuestro Estado social el que sobrecarga el esfuerzo de la familia en el ámbito de la reproducción social y, por ende, estimula ulteriormente el desarrollo del trabajo irregular. Al fin y al cabo, más Estado social quiere decir más empleos regulares en el mercado, menos sobrecarga de las familias y menor necesidad de que la demanda insolvente, en la medida en que no es satisfecha en el ámbito del trabajo no remunerado, movilice un segmento del empleo irregular, que es ocupado cada vez más por inmigrantes.

Es posible que durante los próximos años el Estado español pretenda seguir inhibiéndose en sus funciones de apoyo a la reproducción social, renunciando así a explotar el nuevo yacimiento de empleo probablemente más importante de que se dispone, pero no es probable que la familia, es decir la mujer, siga soportando el esfuerzo actual. Con su bajísima fecundidad, su tardía maternidad, sus niveles educativos creciendo por encima de los masculinos y su tasa de actividad en ascenso, la mujer española está diciendo que la producción económica y la reproducción social han de buscar el abrigo de otros puertos. 
Si nos situamos en perspectiva marxista, podemos decir que la necesidad de buscar puertos alternativos al trabajo doméstico no sólo deriva de la rebelión de las mujeres, sino también de las exigencias de la acumulación capitalista. Ésta «necesita, para su desarrollo, un medio ambiente de formaciones sociales no capitalistas; va avanzando en constante metabolismo con ellas, y sólo puede subsistir mientras dispone de este medio ambiente» (Luxemburgo, 1967: 281). Dicho en otras palabras, el desarrollo capitalista implica tendencialmente la mercantilización de todas las relaciones sociales. En las sociedades avanzadas, el sector doméstico es probablemente el menos colonizado por la expansión de las relaciones de producción capitalistas, que ya ha engullido la economía campesina, las actividades industriales y buena parte de la economía substantiva de servicios. La racionalización de la producción de valores de uso característica del sector doméstico puede proceder por dos vías:

1) la vía del capitalismo socialdemócrata escandinavo, con sus políticas redistributivas y de desarrollo de los servicios sociales (más empleo regular estable);

2) la vía del capitalismo neoliberal anglosajón, con sus políticas desreguladoras y el correspondiente desarrollo de los servicios personales (más empleo regular o irregular en todo caso precario). Ambas maneras de proceder no son incompatibles con un cambio en la división sexual del trabajo dentro de lo que quede del sector doméstico. Este cambio parece en todo caso inevitable si se considera que determinadas relaciones sociales deben seguir permaneciendo al margen tanto de la mercantilización como de la burocratización, lo cual implica a su vez articular estrategias de conciliación de la vida laboral y familiar y, quizás, potenciar el tercer sector.

\section{Post scriptum}

A finales de marzo de 2005, pocos días después de haber corregido y devuelto a PAPERS las galeradas de este artículo, tuve conocimiento de que el Instituto de la Mujer (MTAS) estaba ultimando la publicación de un estudio muy relacionado con mi objeto de análisis: La presencia de las mujeres en el empleo irregular (con especial atención a las empleadas de hogar). Entendiendo que no podía dejar de tenerlo en cuenta, me puse en contacto con el Instituto, que tuvo la gentileza de facilitarme una versión "casi definitiva» del mismo en soporte magnético. Sólo he podido examinarlo de manera precipitada, pero al menos quiero dejar constancia aquí de sus conclusiones más relevantes en lo que se refiere al volumen de la bolsa de empleo irregular, así como esbozar algunas consideraciones críticas.

La comparación entre los datos de ocupación estimada por la EPA y los del registro de trabajadores afiliados a la Seguridad Social en situación de alta laboral (depurados) permite deducir que, en 2002, considerando sólo aquellas ramas de actividad donde la ocupación supera a la afiliación, hay: 
1) 522.700 mujeres ocupadas no afiliadas, es decir un $16,7 \%$ de la ocupación femenina total en las ramas consideradas. Para 1998, las cifras correspondientes son 363.800 y 16,4\%. (En el marco del estudio también se ha llevado a cabo una encuesta a mujeres trabajadoras de la cual se deduce que, en 2003, el 30,2\% de las ocupadas están en situación irregular).

2) 815.600 hombres ocupados no afiliados $(12,7 \%)$.

Los datos de ocupación y afiliación se ofrecen desagregados en veintinueve ramas de actividad. En diez de esas ramas hay más mujeres afiliadas que ocupadas, y se registra una sobreafiliación de 509.000 mujeres. En el caso de los hombres, son seis las ramas que registran más afiliación que ocupación, con un total de 391.000 efectivos.

Paradójicamente, al desagregar los datos de irregularidad en función del origen de los trabajadores (españoles o inmigrantes), la cifra de irregulares autóctonos (586.300 mujeres y 1.015 .400 hombres) supera el total de irregulares. Este sorprendente resultado se explica fundamentalmente en términos de la tendencia de la EPA a subestimar la presencia de inmigrantes en el mercado de trabajo español, e incluso el nivel de ocupación de los autóctonos. De hecho, las extranjeras afiliadas superan a las ocupadas virtualmente en todas las ramas.

La explicación apuntada es en general plausible, pero no totalmente satisfactoria. Mi impresión es que la estimación obtenida del empleo irregular puede estar sesgada por la propia metodología utilizada, y que algunos de los resultados (por lo demás significativos) del estudio deben ser objeto de una reflexión más profunda. Así, el hecho de que la sobreafiliación se dé también entre los españoles y en un número relativamente significativo de ramas de actividad (jincluyendo la Administración pública!) obliga a formular hipótesis explicativas alternativas a las supuestas deficiencias de la EPA. El mismo estudio facilita pistas al respecto cuando destaca el aumento de la afiliación femenina en la agricultura entre 1998 y 2002, mientras desciende la ocupación. Es posible que muchas mujeres estén sosteniendo a su costa una situación de alta en el Régimen Especial Agrario, a pesar de no estar ocupadas, a fin de poder acceder a prestaciones; consideración que puede hacerse extensiva también al Régimen Especial de Trabajadores Autónomos, a todas las actividades en las que abundan las unidades productivas de carácter familiar y a los hombres. En cuanto a la Administración pública, me atrevo a sugerir, entre otras explicaciones posibles, que algunos ayuntamientos pueden haber decidido financiar las cotizaciones sociales (y aun los salarios) de personas no ocupadas en situación de grave precariedad económica, ante las deficiencias de nuestro estado social, si bien tampoco descartaría motivaciones relacionadas con el nepotismo. En todos estos casos, la EPA no estaría subestimando la ocupación. Por otra parte, no es en absoluto improbable que en las ramas de actividad con sobreafiliación haya también empleo irregular.

Más en general, entiendo que hay que ser muy cuidadoso a la hora de cuestionar la consistencia técnica de la EPA, pues se corre el riesgo de acabar dudan- 
do de la gravedad del paro en España. Me temo que un estadístico experto tendría diversas objeciones que formular a las siguientes afirmaciones, hechas en el estudio, relacionadas con las supuestas debilidades de esta encuesta: «Al considerar que una persona es ocupada sólo con referencia a la semana en que se realiza la encuesta, la EPA no capta de forma adecuada situaciones laborales esporádicas, que en muchas ocasiones son susceptibles de irregularidad laboral. [...], como toda encuesta, la EPA depende de la actitud de la persona encuestada a decir o no la verdad sobre su situación laboral.» Sin embargo, como se señala en el estudio, es cierto que la EPA, al trabajar con datos censales y ante la dimensión que ha adquirido el flujo de inmigrantes desde 2001, está subestimando gravemente la ocupación extranjera. De hecho, el INE se ha visto obligado a revisar al alza los datos de población con que trabaja y, en consecuencia, está procediendo a recalcular los resultados de la EPA de los últimos años.

En todo caso, no quiero acabar esta apostilla sin reconocer explícitamente que el estudio que la ha provocado es una contribución valiosa que enriquece de manera sustancial el conocimiento de las condiciones de vida y trabajo, así como de las características, aspiraciones, opiniones, inquietudes y perspectivas de las mujeres ocupadas en la economía sumergida.

[E. S. 6 de abril de 2005]

\section{Bibliografía}

Alañón, Ángel; Gómez, Miguel (2003). «Una evaluación del grado de incumplimiento fiscal para las provincias españolas». Papeles de Trabajo, n. ${ }^{\circ} 3$. Madrid: Instituto de Estudios Fiscales.

ARAngo, Jesús (1999). La protección por desempleo en España. Madrid: Consejo Económico y Social.

BAGNASCO, Arnaldo (a cargo de) (1986). L'altra metà dell'economia. La ricerca internazionale sull'economia informale. Nápoles: Liguori.

BANYULS, Josep y otros (2002/2003). «Empleo informal y precariedad laboral: las empleadas de hogar». Sociología del Trabajo, n. ${ }^{\circ}$ 47, p. 75-105.

BENERÍA, Lourdes (1999). «El debate inconcluso sobre el trabajo no remunerado». Revista Internacional del Trabajo, n. ${ }^{\circ}$ 3, p. 321-346.

CARRASQUer, Pilar y otros (1998). «El trabajo reproductivo». Papers, 55, p. 95-114.

COMisión de las COMUnidades Europeas (1990). El empleo en Europa 1989. Luxemburgo: Oficina de publicaciones oficiales de las Comunidades Europeas.

COMISIÓN EUROPEA (1998). Comunicación de la Comisión sobre el Trabajo no Declarado. Bruselas: COM (98) - 219.

COSTA, Xavier (2002). «La integración de los inmigrantes en la fiesta de las fallas». Arxius, n. ${ }^{\circ}$ 6, p. 211-230.

- (2002a). "Festive Identity: Personal and Collective Identity in the Fire Carnival of the "Fallas" (València, Spain)». Social Identities, n. ${ }^{\circ}$ 2, p. 321-345.

DURÁN, María Ángeles (1995). «Invitación al análisis sociológico de la contabilidad nacional». Politica y Sociedad, n. ${ }^{\circ} 19$, p. 83-99.

- (1997). «El papel de mujeres y hombres en la economía española». Información Comercial Española, n. ${ }^{\circ}$ 760, p. 9-29. 
- (1999). Los costes invisibles de la enfermedad. Bilbao: Fundación BBV.

- (2000). Si Aristóteles levantara la cabeza. Quince ensayos sobre las ciencias y las letras. Madrid: Cátedra.

- (2000a). «Concentración y reparto del trabajo no remunerado en los hogares». Cuadernos de Relaciones Laborales, n. ${ }^{\circ}$ 17, p. 91-122.

EsPING-ANDERSEN, Gosta (2000). Fundamentos sociales de las economias postindustriales. Barcelona: Ariel.

Instituto NaCiOnAL De Estadística (2004). Encuesta de empleo del tiempo 20022003. Madrid.

LUXEMBURGO, Rosa (1967). La acumulación del capital. México: Grijalbo.

Meseguer, Pablo (2003). «Trabajo doméstico y relación salarial». Cuadernos de Relaciones Laborales, n. ${ }^{\circ} 21$, p. 127-144.

MingIONE, Enzo (1993). Las sociedades fragmentadas. Una sociología de la vida económica más allá del paradigma del mercado. Madrid: Ministerio de Trabajo y Seguridad Social.

Ministerio de Trabajo y Asuntos Sociales. Encuesta de calidad de vida en el trabajo 2003. Madrid.

MolTó, María Luisa y otros (1991). Condiciones de vida y trabajo en la Comunidad Valenciana. Valencia: Conselleria de Treball i Seguretat Social.

MonZÓn, José Luis (dir.) (2003). El Tercer Sector no lucrativo en el Mediterráneo. La economía social de no mercado. I. España, Francia, Grecia, Italia y Portugal. Valencia: CIRIEC-ESPAÑA.

Muro, Juan y otros (1988). Análisis de las condiciones de vida y trabajo en España. Madrid: Ministerio de Economía y Hacienda, Secretaría de Estado de Economía.

NAVARRO, Vicenç (2002). Bienestar insuficiente, democracia incompleta. Sobre lo que no se habla en nuestro país. Barcelona: Anagrama.

NAVARro, Vicenç; Quiroga, A. (2003). «La protección social en España y su desconvergencia con la Unión Europea». Sistema, n. ${ }^{\circ}$ 177, p. 3-37.

Offe, Claus; Heinze, R.; Braley, A. (1992). Beyond Employment: Time, Work and the Informal Economy. Cambridge: Polity Press.

PÉreZ, Gabriel (2000). «El voluntariado entre la libertad y la necesidad social». Cuadernos de Relaciones Laborales, n. ${ }^{\circ}$ 17, p. 123-137.

PolanYI, Karl (1994). El sustento del hombre. Barcelona: Mondadori.

PORTES, Alejandro; CASTElls, M.; BeNTON, L. (1989). The Informal Economy: Studies in Advanced and Less Developed Countries. Baltimore: The Johns Hopkins University Press.

RENOOY, Piet y otros (2004). Undeclared work in an elarged Union. Final report. Comisión Europea. Manuscrito.

REYNERI, Emilio (1996). Sociologia del mercato del lavoro. Bolonia: Il Mulino.

RUIZ, José Ignacio (dir.) (2000). El sector no lucrativo en España. Bilbao: Fundación BBV.

SANCHIS, Enric (1984). El trabajo a domicilio en el Pais Valenciano. Madrid: Instituto de la Mujer. Ministerio de Cultura.

- (comp.) (1988). La otra economía. Trabajo negro y sector informal. Valencia: Institució Valenciana d'Estudis i Investigació.

SCHNEIDER, Friedrich; EnSTE, Dominik H. (2000). «Shadow Economies: Size, Causes and Consequences». Journal of Economic Literature, vol. 38, p. 77-114.

TOHARIA, Luis (dir.) (1998). El mercado de trabajo en España. Madrid: McGraw-Hill.

VV. AA. (1986). Condiciones de vida y trabajo en España. Madrid: Secretaría General de Economía y Planificación. Centro de Investigaciones Sociológicas. 
VV. AA. (2000). Empleo y trabajo voluntario en las ONG de acción social. Madrid: MTAS-Fundación Tomillo.

WARING, Marilyn (1994). Si las mujeres contaran. Una nueva economía feminista. Madrid: Vindicación Feminista.

Williams, Colin C.; WinDEBANK, Jan (1998). Informal Employment in the Advanced Economies. Implications for Work and Welfare. Londres: Routledge.

YbarRa, Josep-Antoni; HuRTAdo, J.; SAn Miguel, B. (2001). «La economía sumergida revisitada». Sociología del Trabajo, n. ${ }^{\circ} 43$, p. 29-70.

- (2002). «La economía sumergida en España: un viaje sin retorno». Sistema, n. ${ }^{\circ} 168$ 169 , p. 247-282. 